Paediatrics,University of Munster, Germany (Weglage J et al. Eur I Pediatr March 1996;155:200-204). These attention deficits probably resulted from impairment of frontal lobe function and could probably be avoided by a stricter dietary control of the PKU. Phenylalanine inhibits the synthesis of dopamine and serotonin as well as the uptake of tyrosine and tryptophan.

\title{
INFRARED MOTION ANALYSIS OF HYPERACTIVE CHILDREN
}

Movement patterns of 18 boys with ADHD and 11 normal controls were recorded using an infrared video and motion analysis system during a continuous performance task (CPT) at the Department of Psychiatry, Harvard Medical School, Boston, and the McLean Hospital, Belmont, MA. Compared to controls, subjects with ADHD moved their extremities and head more than twice as often, they covered a 3.4-fold greater distance and a 4-fold greater area. Whole body movements were also 3 to 4 times more frequent and covered a greater distance. Their responses on the CPT were slower and more variable. The less complex and more linear movement patterns of ADHD children correlated with teacher ratings of overactivity-inattention. (Teicher MH et al. Objective measurement of hyperactivity and attentional problems in ADHD. I Am Acad Child Adolesc Psychiatry March 1996;35:334-342). (Reprints: Dr Teicher, McLean Hospital, 115 Mill Street, Belmont, MA 02178).

COMMENT. In addition to the infrared motion analysis of overactivity in ADHD children, the authors used a wristwatch sized "actigraph"worn on a belt to measure activity levels (results to be published separately). Previous publications describing similar objective measurements of hyperactivity were apparently overlooked.

Schulman JL and Reisman JM, at Children's Memorial Hospital, Chicago, devised an "actometer," an automatically winding calender wristwatch with the pendulum connected directly to the hands of the watch, to measure movements of the arms and legs (Amer I Ment Defic 1959;64:455).

Millichap JG et al, also at Children's Memorial and Northwestern Univ Med School, employed the actometer to demonstrate significant lessening of overactivity in hyperactive children treated with methylphenidate (Am I Dis Child 1968;116:235). The "actometer" was worn on the wrist of the nondominant arm during neuropsychological test periods, and activity was measured in units of hours and minutes. The effect of methylphenidate was related to the level of motor activity before treatment; the more active patients were benefited the most by stimulant medication. This simple objective measure of motor activity could be of value, not only in experimental situations but also, in confirming the diagnosis of ADHD when parent and teacher impressions are in disagreement.

\section{DSM-III-R cf DSM-IV DIAGNOSTIC CRITERIA FOR ADHD}

Teacher-reported prevalence rates for attention-deficit hyperactivity disorder (ADHD) using DSM-IV and DSM-III-R criteria were compared in a middle Tennessee county during the 1993-94 academic year and analysed by subtypes at Vanderbilt University, Nashville, TN. Rating scales for 8258 children were completed by 398 teachers. Prevalence rates were $7.3 \%$ for ADHD using DSM-III-R diagnostic criteria; 5.4\% for ADHD, inattentive type (AD); $2.4 \%$ for hyperactive-impulsive type(HI); and $3.6 \%$ for combined type (CT) using DSM-IV criteria. Boys outnumbered girls with a 4:1 ratio for ADHDHI and 2:1 for ADHD-AD. The number of children meeting criteria for the total of all three DSM-IV subtypes $(11.4 \%)$ was $57 \%$ greater than those with ADHD 